\title{
IMS-3, SYNTHESIS, and MR RESCUE: No Disaster, but Down to Earth
}

\author{
R. von Kummer · J. Gerber
}

Accepted: 14 February 2013 / Published online: 1 March 2013

(C) Springer-Verlag Berlin Heidelberg 2013

After an infusion of recombinant tissue plasminogen activator (rt-PA), the proportions of stroke patients without disability (modified Rankin score $(\mathrm{mRS}):<2$ ) varied in positive randomized trials between $39 \%$ (NINDS 2) and $52 \%$ (ECASS 3) [1, 2]. This success in ischemic stroke treatment was impressive and is now guiding stroke management since almost 20 years. Intravenous (IV) rt-PA became the Holy Grail of stroke treatment, and any increase in the proportion of patients being treated with rt-PA is regarded a success. It is widely ignored that the absolute risk reduction for death and disability was $13 \%$ (NINDS 2 with an imbalance at baseline favoring rt-PA) and 7\% (ECASS 3) only. Other rt-PA trials did not show a significant effect. Moreover, a combined analysis of all major randomized trials with IV rt-PA showed the disappearance of any beneficial effect within 6 h of stroke onset [3]. Today, stroke physicians treat less than $10 \%$ of their patients with IV rt-PA following international guidelines. Among these happy patients, only few (maximum 13\%) benefit from this treatment. In the real world, IV rt-PA treatment thus reduces disability and death in less than $1 \%$ of an ischemic stroke population.

The efficiency of rt-PA treatment is small due to three major factors: (1) The trials did not control arterial pathology and included patients without arterial occlusions having an excellent spontaneous prognosis. (2) Arterial recanalization and tissue reperfusion was not achieved while ischemic brain tissue was still viable. (3) Arterial recanalization did not prevent functional impairment because major portions of the ischemic territory were already irreversibly injured

R. von Kummer $(\bowtie) \cdot$ J. Gerber

Abteilung Neuroradiologie,

Universitätsklinikum Carl Gustav Carus,

Fetscherstr. 74, 01307 Dresden, Germany

e-mail: ruediger.vonkummer@uniklinikum-dresden.de or side effects like brain hemorrhage impaired possible beneficial effects.

About $30 \%$ of acute ischemic stroke patients do not have arterial occlusions as assessed by digital subtraction angiography within the first $6 \mathrm{~h}$ of stroke onset [4]. In this time window, the same proportion of patients does not show ischemic edema on computed tomography (CT) [5]. Patients without arterial occlusions as assessed by CT angiography within $6 \mathrm{~h}$ of stroke onset had good clinical outcomes (mRS $<3$ ) in $60 \%$ whether they were treated with rt-PA or not [6]. Patients with major artery occlusions, however, often do not benefit from IV rt-PA and may have already extended ischemic edema that may deteriorate with tissue reperfusion.

A few and very recent trials of intraarterial (IA) treatment studied clinical outcomes in more severely ill patients with proved obstruction of major brain arteries. The Prolyse in Acute Cerebral Thromboembolism trial (PROACT) II randomized 180 acute ischemic stroke patients with middle cerebral artery (MCA) occlusions within $6 \mathrm{~h}$ of symptom onset [7]. Only $25 \%$ of placebo treated patients had good clinical outcomes $(\mathrm{mRS}<3)$. The IA treatment with prourokinase enhanced this proportion to $40 \%(p=0.04)$.

The recently prematurely terminated Interventional Management of Stroke Trial 3 (IMS-3) compared endovascular treatment after IV rt-PA to standard IV rt-PA alone in 656 patients with a baseline National Institutes of Health Stroke Scale Score (NIHSS) >9 to identify those patients with a high likelihood of major arterial occlusion on subsequent angiography [8]. It turned out that 100 patients randomized to IA treatment $(24 \%)$ did not receive IA treatment after IV rt-PA by various reasons (early clinical improvement or deterioration, absence of clot, and technical failures). Reperfusion rates as graded on digital subtraction angiography with the Thrombolysis in Cerebral Infarction score (TICI) were below $50 \%$ for TICI $2 \mathrm{~b} / 3$ ( $>50 \%$ reperfused arteries 
within the territory of the recanalized artery: internal carotid, middle cerebral, or basilar). The trial was stopped for futility with good clinical outcomes $(\mathrm{mRS}<3)$ in $38.7 \%$ of IV rt-PA patients and in $40.8 \%$ of patients who had received IA therapy after IV rt-PA. (IA rt-PA $(N=142)$, EKOS $(N=22)$, Merci $(N=95)$ Penumbra aspiration $(N=54)$, thrombectomy with Solitaire $(N=5))$ It is not yet analyzed whether the perprotocol treated endovascular group had a benefit compared to IV treatment alone and whether TICI $2 \mathrm{~b} / 3$ reperfusion was associated with improved clinical outcome.

A real world approach was chosen by the Synthesis Expansion investigators. They tested the hypothesis whether IA treatment is superior to IV treatment irrespective of the stroke patients' vessel status [9]. They randomized 362 patients for IV rt-PA or endovascular treatment; among them, patients with arterial wall dissections or with microvessel disease. Based on an intend-to-treat-analysis, good clinical outcomes were achieved in $30.4 \%$ of patients after IA treatment and in $34.8 \%$ after IV rt-PA. Some of the patients in the endovascular group did not receive IA therapy, however, and some patients were treated with thrombectomy after IV rt-PA. The authors admit that they cannot exclude the possibility that endovascular treatment is superior to standard intravenous rt-PA in patients selected on the basis of computed tomography angiography (CTA)or magnetic resonance angiography (MRA)-findings.

Another recent trial, Mechanical Retrieval and Recanalization of Stroke Clots Using Embolectomy (MR RESCUE), aimed to show that multimodal MRI can identify the appropriate patients for endovascular treatment in ischemic stroke [10]. The authors randomized 127 patients to embolectomy with the Merci retriever or Penumbra device or standard care and studied clinical outcomes in subgroups with and without a "penumbral pattern" on MRI of each treatment arm. They did not observe better revascularization, tissue reperfusion, and clinical outcomes in the embolectomy group compared to the standard care group and could not show that multimodal MRI helps to find the appropriate patients for this type of treatment.

We learn from these trials that less than $40 \%$ of acute stroke patients with major artery occlusion and endovascular treatment had good clinical outcomes after IA treatment. This impression is supported by a recent outcome analysis of 3,864 stroke patients receiving clot retrieval between 2006 and 2008 in the United States. In-hospital mortality was $24 \%$ and the rate of discharge to a long-term facility was $51 \%$ [11]. It appears hard to beat, the rather small beneficial effect of IV treatment.

How can we do better? "Recanalization" associated with good outcomes needs a more precise definition. Thrombolysis in Myocardial Infarction (TIMI) $2 / 3$ or TICI $2 / 3$ likely represents reperfusion states not associated with functional recovery. Achievement of TICI $2 b / 3$ is required.
It is obvious that the recanalization rates achieved in these trials were too low to really test the effect of arterial recanalization and tissue reperfusion. Furthermore, we should consider that patients benefitting from IV treatment are different from patients benefitting from IA treatment. Criteria for patient selection were poor in IMS-3 and SYNTHESIS that included patient without arterial occlusion and without endovascular treatment into the endovascular arm. In theory, the key is early arterial recanalization and tissue reperfusion in patients without extended ischemic damage. The assessment of arterial obstruction and ischemic damage with CT/ CTA or MRI/MRA are the most important diagnostic steps after a quick clinical examination. Patients with major artery occlusions and patients without ischemic damage (hypodensity on $\mathrm{CT}$, hyperintensity on diffusion weighted imaging (DWI)) exceeding $33-50 \%$ of the affected territory may have a chance to benefit from IA therapy. The reduction of time from stroke onset to recanalization enhances the probability for good clinical outcome [12]. Endovascular treatment, however, requires time, specific logistics, specialists, and skills that are not widespread. As scientific evidence is still lacking for the fact that IA treatment under real world conditions can improve clinical outcomes, it should be performed only by following prospective protocols that document arterial occlusion at baseline, grade of recanalization and reperfusion, time to recanalization, and predefined clinical endpoints. It is of interest that a current randomized trial testing the efficacy and safety of IV desmoteplase in a late time window randomize ischemic stroke patients with proved major arterial occlusions, but no major ischemic damage [13]. Scientific evidence is urgently needed to show that treatment of ischemic stroke can do much better if patients are carefully and quickly identified for the most appropriate treatment. For real world conditions, it would be of advantage if a drug given IV immediately after diagnosis can rescue more stroke patients than endovascular treatment with the most sophisticated devices. Only randomized trials can provide the evidence. To neglect this and continue with endovascular treatment on a routine basis rather than in controlled trials will probably render poor service to stroke patients and also to the further development of endovascular treatment approaches itself.

\section{References}

1. NINDS rt-PA Stroke Study Group. Tissue plasminogen activator for acute ischemic stroke. N Engl J Med. 1995;333:1581-7.

2. Hacke W, Kaste M, Bluhmki E, Brozman M, Davalos A, Guidetti D, Larrue V, Lees KR, Medeghri Z, Machnig T, Schneider D, von Kummer R, Wahlgren N, Toni D, ECASS Investigators. Thrombolysis with alteplase 3 to 4.5 hours after acute ischemic stroke. N Engl J Med. 2008;359:1317-29. 
3. Lees KR, Bluhmki E, von Kummer R, Brott TG, Toni D, Grotta JC, Albers GW, Kaste M, Marler JR, Hamilton SA, Tilley BC, Davis SM, Donnan GA, Hacke W, ECASS, ATLANTIS, NINDS and EPITHET rt-PA Study Group, Allen K, Mau J, Meier D, del Zoppo G, De Silva DA, Butcher KS, Parsons MW, Barber PA, Levi C, Bladin C, Byrnes G. Time to treatment with intravenous alteplase and outcome in stroke: an updated pooled analysis of ECASS, ATLANTIS, NINDS, and EPITHET trials. Lancet. 2010;375:1695-703.

4. Kassem-Moussa H, Graffagnino C. Non-arterial occlusion at different time-points after stroke onset. Arch Neurol. 2002;59:1870-3.

5. von Kummer R, Bourquain H, Bastianello S, Bozzao L, Manelfe C, Meier D, Hacke W, for the ECASS II Group. Early prediction of irreversible brain damage after ischemic stroke by computed tomography. Radiology. 2001;219:95-100.

6. Shobha N, Bhatia R, Boyko M, Tymchuk S, Kumarpillai G, Smith E, Demchuk AM. Outcomes in acute ischemic stroke presenting with disabling neurological deficits without intracranial vascular occlusion. Int J Stroke. 2011;6:392-7.

7. Furlan A, Higashida R, Wechsler L, Gent M, Rowley H, Kase C, Pessin M, Ahuja A, Callahan F, Clark WM, Silver F, Rivera F, for the PROACT investigators. Intra-arterial prourokinase for acute ischemic stroke. The PROACT II study: a randomized controlled trial. Prolyse in Acute Cerebral Thromboembolism. JAMA. 1999;282:2003-11.

8. Broderick JP, Palesch YY, Demchuk AM, Yeatts SD, Khatri P, Hill MD, Jauch EC, Jovin TG, Yan B, Silver FL, von Kummer R, Molina CA, Demaerschalk BM, Budzik R, Clark WM, Zaidat OO, Malisch TW, Goyal M, Schonewille WJ, Mazighi M, Engelter S, Anderson C, Spilker J, Carrozzella J, Ryckborst KJ Janis LS, Martin RL, Foster LD, Tomsick TA, for the IMS III Investigators. Endovascular therapy after intravenous t-PA versus t-PA alone for Stroke. N Eng J Med. 2013, doi:10.1056/NEJMoa1214300 (published online on February 7, 2013).
9. Ciccone A, Valvassori L, Nichelatti M, Sgoifo A, Ponzio M, Sterzi R, Boccardi E, for the SYNTHESIS Expansion Inverstigators. Endovascular treatment for acute ischemic stroke. N Eng J Med. 2013. doi:10.1056/NEJMoa1213701 (published online on February 6, 2013).

10. Kidwell CS, Jahan R, Gornbei J, Alger JR, Nenov V, Ajani Z, Feng L, Meyer BC, Olson S, Schwamm LH, Yoo AJ, Marshall RS, Meyers PM, Yavagal DR, Wintermark M, Guzy J, Starkman $\mathrm{S}$, Saver JL, for the MR RESCUE investigators. A trial of imaging selection and endovascular treatment for ischemic stroke. N Engl J Med. 2013. doi:10.1056/NEJMoa1212793 (published online on February 8, 2013).

11. Brinjikji W, Rabinstein AA, Kallmes DF, Cloft HJ. Patients' outcome with endovascular embolectomy therapy for acute ischemic stroke: a study of the national inpatient sample: 2006 to 2008 . Stroke. 2011;42:1648-52.

12. Khatri P, Abruzzo T, Yeatts SD, Nichols C, Broderick JP, Tomsick TA, IMS I and II Investigators. Good clinical outcome after ischemic stroke with successful revascularization is time-dependent. Neurology. 2009;73:1066-72.

13. von Kummer R, Albers GW, Mori E, on behalf of the DIAS Steering Committees. The Desmoteplase in Acute Ischaemic Stroke (DIAS) clinical trial programme. Int J Stroke. 2012;7:589-96. 